\title{
Handel med stjålen kulturarv: UNESCO's kulturkonventioner og Danmarks muligheder
}

\author{
VINNIE NøRSKOV*
}

Title: Trade in stolen cultural heritage. UNESCO conventions and the role of Denmark

Abstract: During the Summer of 2006, the Danish press investigated the Danish auction houses and museums in order to test whether objects knowingly smuggled out of their countries of origin were bought and sold in Denmark. This has raised the question whether Danish legislation is adequate in relation to protecting the world's cultural heritage, and led to the organisation of the public meeting in March 2007 to discuss the issue. The invited speakers touched on subjects that included the destruction of Iraq's cultural heritage, the lack of legal tools for returning objects illegally exported from South America, experience with ratification of the international conventions in Norway and the Netherlands, and questions about the role of both the auction business and the museums in trading in stolen cultural property. As a very positive result of the meeting, the Danish Minister of Culture announced that Denmark will work on ratifying the 1995 UNIDROIT Convention on Stolen or Illegally Exported Cultural Objects.

Keywords: Protection of cultural heritage, illegal trade, stolen cultural objects, legislation, international conventions, destruction of archaeological sites, museum acquisitions, auction houses, collectors.

Den 9. marts 2007 afholdt den danske UNESCO-nationalkommission, dansk ICOM, Det kongelige Bibliotek og Nationalmuseet et debatmøde med titlen Handel med stjalen kulturarv. De fleste inden for den danske museumsverden vil være bekendt med den debat, som har kørt i specielt Dagbladet Information og Politiken siden sommeren 2006 omkring enkeltsager angående køb og salg af kulturarv i
Danmark. Der har været fokus på salg af illegale genstande hos de store danske auktionshuse Bruun Rasmussen og Museumsbygningen, erhvervelser af genstande uden proveniens af Ny Carlsberg Glyptotek og Davids Samling, samt enkelte sager som den såkaldte Lyngbysag, hvor en stor samling af genstande fra Sydamerika blev fundet i en villa tilhørende kunstsamleren Jan Erik Pelle i Lyngby. ${ }^{1}$ 
122 Denne opmærksom fra pressen var en væsentlig grund til at afholde mødet, som arrangørerne skriver, for at sætte 'fokus på emnet i en bredere kreds'.

Handel med stjålen kulturarv har været et udbredt fænomen siden det at samle blev en integreret del af den vestlige civilisation. Fænomenets udvikling kan studeres ud fra udviklingen af lovgivningen inden for kulturarvsbeskyttelse, en lovgivning som starter så langt tilbage som i 1400-tallet med de første pavelige love til beskyttelse af monumenter $\mathrm{i}$ Rom. Allerede i 1600-tallet introduceredes fænomenet eksporttilladelse, hvilket er det første tegn på et grænseoverskridende for ikke at sige globalt problem (Nørskov 2002: 83). Indtil midten af det 20. århundrede var beskyttelsen af kulturarven et nationalt problem udtrykt gennem national lovgivning. Den internationale dimension har dog fået overvægt i den sidste halvdel af det 20. århundrede, hvilket afspejles i oprettelsen af UNESCO og introduktionen af UNESCO's konventioner til beskyttelse af kulturarven. Den første konvention kom i kølvandet af 2. Verdenskrig og relaterede sig til beskyttelse af kultur i krigssituationer, Hague konventionen fra 1954 om beskyttelse af kulturvardier $i$ tilfalde af vabnet konflikt, ${ }^{2}$ efterfølgende kom der fokus på problemerne omkring den illegale handel med kulturarv, hvilket førte til vedtagelsen af UNESCOs konvention om midlerne til at forbyde og forhindre ulovlig import, eksport og ejendomsoverdragelse af kulturgenstande i $1970 .^{3}$ Denne konvention blev først ratificeret og implementeret i dansk lovgivning i 2003. De involverede ministerier har i flere omgange vurderet, om Danmark skulle tiltræde konventionen, men det er blevet afvist af forskellige grunde. Dels anså man det for temmelig omfangende at implementere de krav, som kon- ventionen stillede angående registrering og beskyttelse af den danske kulturarv og restriktioner $\mathrm{i}$ import af kulturarv fra andre lande. Samtidig har der på det tidspunkt ikke været noget udpræget ønske fra museumsverdenen om at tiltræde konventionen. Det tog 30 år at ændre disse forhold. I et notat om ratifikationen fra den 27. november 2002 skriver kulturministeren, at en tiltrædelse længe har været et ønske fra museumsverdenen og andre kulturinstitutioner. Beskyttelsen af den danske kulturarv er nu fuldt ud dækket i den danske lovgivning, og der er tilføjet en paragraf i museumsloven fra 2001, som pålægger museerne ikke at erhverve genstande uden legal proveniens. Alt i alt blev det i 2002 anset for at være en positiv politisk beslutning endelig at tiltræde konventionen samtidig med at det var uden omkostninger, da kulturministeriet ikke fandt, at tiltrædelsen krævede en ændret lovgivning.

Det har dog vist sig ikke helt at holde stik, og det er på den baggrund, at debatmødet på Nationalmuseet har sin berettigelse. Mødet blev åbnet af kulturminister Brian Mikkelsen, som i sin tale fokuserede på den internationale udfordring, der ligger $i$ at beskytte kultarven $\mathrm{i}$ en globaliseret verden, hvor situationen er forskellig fra land til land. Han fremhævede to elementer til forhindring af den illegale handel med kulturarv: 1) kontrol med handelen, hvilket i Danmark sker gennem det internationale politisamarbejde, 2) de internationale konventioner, hvor Danmark som sagt tiltrådte UNESCO konventionen fra $1970 \mathrm{i}$ 2003. Ministeren undrede sig over den kritik,

Magasinerne pà Nationalmu-
seet i Baghdad, juli 2003.
Foto: Ingolf Thuesen. 
HANDEL MED STJÅLEN KULTURARV: UNESCO'S KULTURKONVENTIONER OG DANMARKS MULIGHEDER

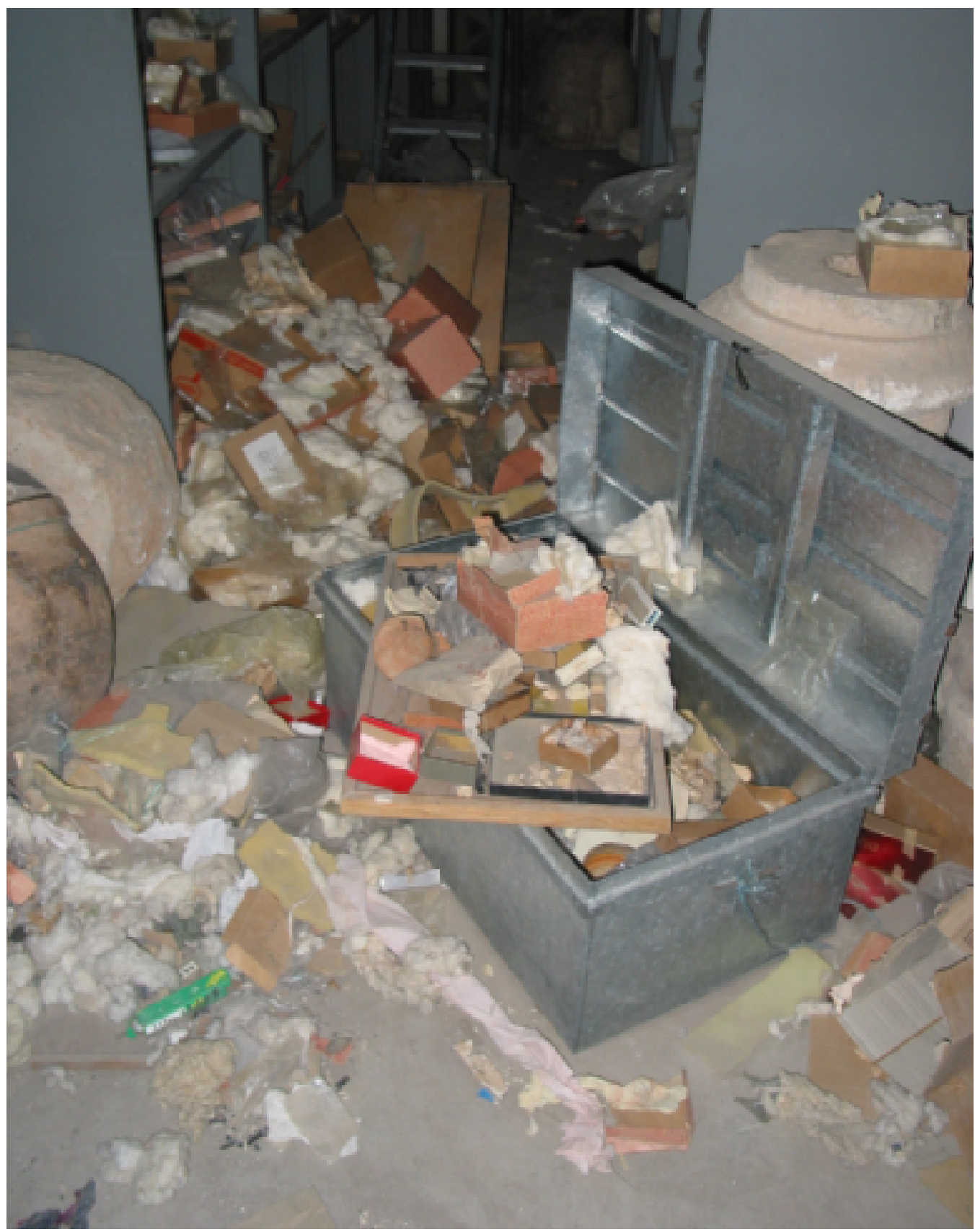


124 der har været vedrørende en manglende følgelovgivning, idet kulturministeriet netop har tolket konventionens krav omkring kontrol af import som en nødvendig revision af museumsloven. Sagen omkring auktionshusenes villighed til at auktionere genstande, som de fik at vide var illegalt smuglet ud af hhv. Kina og Afghanistan, og den såkaldte Lyngbysag viser dog, at det ikke er nok at lovgive omkring statsanerkendte museers erhvervelsespolitik. Der er en lang række spillere på den internationale kunsthandelsscene i form af antikvitetshandlere, auktionshuse, private samlere og private museer, som ikke er underlagt museumsloven og således ikke kan retsforfølges, fordi der ikke er lavet nogen følgelovgivning i forbindelse med ratifikationen af UNESCO konventionen.

I 1995 blev den såkaldte UNIDROIT konvention om stjålne eller ulovligt eksporterede kulturgenstande vedtaget af UNESCO. ${ }^{4}$ Konventionen er et supplement til 1972-konventionen og fokuserer på det privatsretslige område. Konventionen pålægger det enkelte land at sikre et lovgrundlag for, at ansøgninger om tilbagelevering af kulturgenstande kan komme for en domstol, og den giver ejeren ret til økonomisk godtgørelse, hvis genstanden er erhvervet i "god tro", på engelsk due diligence. Et af de store problemer med UNIDROITkonventionen er, at et andet lands lovgivning skal kunne føre til juridiske tiltag i den personlige ejendomsret i Danmark. Hvis man bruger Lyngbysagen som eksempel, så skal eksportforbudet for peruviansk kulturarv kunne føre til, at Peru kan kræve at få udleveret de peruvianske genstande i kunstsamleren Jan Erik Pelles samling. Kulturministeren kunne på mødet oplyse, at en ratifikation af UNIDROIT konventionen i øjeblikket undersøges i kulturministeriet, og at han arbejder på og forventer en ratifikation i nær fremtid. ${ }^{5}$ En sådan ratifikation vil forhåbentlig kunne rette op på nogle af de problemer, som den manglende følgelovgivning for UNESCO konventionen indbefatter. Men der vil sandsynligvis stadig være et behov for udvidede importrestriktioner, hvor der bl.a. kan hentes inspiration inden for lovgivningen til beskyttelse af truede dyr- og plantearter.

\section{IRAK og Peru}

Arkæolog og institutleder Ingolf Thuesen fra Carsten Niebuhr Instituttet ved Københavns Universitet gav herefter en grundlæggende indføring i kulturarvens betydning for identitet nationalt og globalt ud fra eksemplet Irak, som er et af verdenskulturarvens mest truede områder i øjeblikket. Thuesen har været i Irak i flere omgange siden 2003 som medlem af den eksportgruppe, som UNESCO nedsatte for at vurdere skaderne på Iraks kulturarv som følge af krig og embargo. I dag vurderes det, at 15.000 oldsager eksporteres dagligt fra Irak. Den krise, som verdenssamfundet blev vidner til gennem mediernes optagelser af det plyndrede museum d. 7.-8. april 2003, forværres dag for dag. Plyndringen af museet var faktisk ifølge Thuesen et pressestunt: ved at fremvise et plyndret museum ville man fortælle, at der ikke var mere at komme efter, og dermed beskytte de genstande, som befandt sig på museet (Bogdanos 2005). Den sag, som medierne kastede sig over, var ikke den store katastrofe. Det er derimod den fortsatte plyndring af de mange arkæologiske lokaliteter i Irak, som har stået på siden den første golfkrig i 1991 (Schipper 2005). Det er specielt områderne i det sydlige Irak, hvor f.eks. Umma, i dag Tell Jokha, ligner et månelandskab med små kraterer. Gravrøverne arbejder i skiftehold med 100 
arbejdere af gangen, godt beskyttet af vagter med maskingeværer.

Herefter talte Max de la Fuente Prem, ambassadør for Peru, som har været involveret i Lyngbysagen. Ud af den store samling fundet $\mathrm{i}$ villaen i Lyngby har en specialist fra Nationalmuseet identificeret 119 genstande, som oprindeligt stammer fra Peru og menes at være eksporteret ulovligt fra landet. Det skal dog bevises, hvorfra de er stjålet, hvilket påhviler Peru. Men ud fra den nuværende danske lovgivning kan det faktisk ikke lade sig gøre. Politiet har netop oplyst, at sagen frafaldes, fordi der ikke er beviser på at genstandene er illegale, og samleren kræver nu 10 millioner i erstatning. ${ }^{6}$

\section{HANDEL I DANMARK}

Den svenske arkæolog Staffan Lundén, ansat ved Museion ved Göteborg Universitet, har arbejdet med problemerne omkring illegal handel med oldsager i en del år. Som Peter Watson har Lunden bevæget sig ind i kunsthandlens morads og udgivet sig for at være samler og på den måde fået en række informationer omkring handelen med oldsager i Sverige. ${ }^{7}$ Det var hans samarbejde med to journalister fra Dagbladet Information, som afslørede de danske auktionshuses villighed til at sælge smuglede oldsager. De tre undersøgte også nogle af de danske museer med henblik på at afsløre indkøb af oldsager uden proveniens i nyere tid, og Lundén nævnede Ny Carlsberg Glyptotek, som i 1970'erne erhvervede en del genstande gennem kunsthandleren Robert Hecht, som i øjeblikket bliver retsforfulgt i Italien sammen med tidligere direktør for J.P. Getty Museum i Malibu, Marion True, og Davids Samling, som har erhvervet en række genstande hovedsageligt i 1970'erne, men det seneste er to Koransider erhvervet i 1990, som 125 Tyrkiet har bedt om at få tilbageleveret. ${ }^{8}$ Det var dog ikke muligt at finde nogen helt aktuelle indkøb af genstande uden proveniens på de danske museer. Heldigvis. På trods af det afsluttede Lunden med at konstatere, at der er et "fairly sizeable market" for illegale oldsager i Danmark. Lundéns undersøgelser burde her udvides med en reel undersøgelse af markedet for illegale oldsager i Danmark. Fundet i Lyngby er reelt det eneste konkrete eksempel på en nyere samling af genstande, som i hvert fald delvist har været udbudt til salg, idet nogle af genstandene har været udbudt hos Bruun Rasmussen. En konkret gennemgang af de danske auktionshuses udbud af mulige illegale oldsager har ikke været lavet, men det ville være interessant at efterforske. Ud fra de danske museers indkøb af oldsager $\mathrm{i}$ vore dage mener jeg dog ikke, at man kan påstå, at der er et rimeligt stort marked. Men der er meget lidt kendskab til den aktuelle indsamling blandt private.

\section{ERfaringer fra Norge og Holland}

Den norske arkæolog og seniorrådgiver hos Rigsantikvaren i Norge, Lyder Marstrander, var indbudt til at fortælle om arbejdet med ratifikationen af UNIDROIT-konventionen i Norge, og han stod for et af de væsentligste bidrag på mødet. Ratifikationen bygger på UNESCO-konventionen fra 1970 og EU-direktivet fra 1993 om tilbagelevering af kulturgoder, som er ulovligt fjernet fra et andet EUmedlemslands område mv. Men mens UNESCO-konventionens formål er at hindre illegal handel, så er det væsentligste element i UNIDROIT-konventionen at sætte nogle rammer for de lande og personer, som bliver udsat for illegal handel og som ønsker at få den pågæl- 
dende kulturarv tilbage. I den norske ratifikation er tidsrammen for et krav om tilbagelevering på 3 år, efter at man er blevet bekendt med genstandenes opholdssted. Men aldrig mere end 50 år siden tyveriet er foregået, medmindre det handler om tyveri fra offentlige samlinger. UNIDROIT-konventionen giver mulighed for at gå til det pågældende lands domstol og kræve genstandene udleveret. Det betyder f.eks. at Peru ville have haft mulighed for at bede den danske domstol om at få de peruvianske genstande fra Lyngbyvillaen udleveret, ifald Danmark havde ratificeret konventionen. I Norge er konventionen f.eks. brugt i forbindelse med auktioner, hvor der har været illegale genstande til salg. Konventionen definerer begrebet "god tro" og sætter høje krav til en køber om at sikre sig en legal proveniens. Men hvis køberen kan bevise, at købet af en genstand er gjort i "god tro" om at det var legalt, så har vedkommende også ret til kompensation, hvis genstanden tilbageleveres.

Professor Susan Legêne fra universitetet i Amsterdam gav en interessant analyse af situationen i Holland. I 1982 blev der holdt et europæisk møde i København omkring ratifikation af UNESCO 1970-konventionen. Arkivalier hos den hollandske UNESCO nationalkommision beretter om et møde, hvor to argumenter mod en ratifikation blev fremført: 1) det ville gøre det meget svært for museer at erhverve genstande fra andre lande i fremtiden, hvilket specielt ville være problematisk for de etnografiske museer, og 2) man frygte$\mathrm{de}$, at en ratifikation ville føre til krav om tilbagelevering af genstande, som i mange år havde været i museumseje, for eksempel fra Grækenland og Zaire. Det var specielt England og Frankrig, som her så problemerne, så de påtog sig at lave et udkast til ratifikation af konventionen som så at sige tog højde for de to ting. Den hollandske delegerede ventede dog ikke, men lavede et oplæg som argumenterede for en hollandsk ratifikation - et oplæg som aldrig blev sendt til diskussion i parlamentet. Begrundelsen findes i en række forhold som de involverede ministeriers indbydes konkurrence og forskellige holdninger, kunsthandelens argumenter omkring dels det høje administrative niveau, som en ratifikation ville påkræve, dels udviklingslandenes manglende forståelse for og negligering af deres kulturarv. I øjeblikket er forslaget om ratifikation af UNESCO-konventionen til vurdering efter en pludselig ændring i holdning hos justitsministeriet i 2004. Mens de hollandske museer i dag fuldstændig bakker op om ratifikation af begge konventioner, og pga ICOMs etiske regler og en hollandsk etisk komite, som holder øje med museernes erhvervelsespolitik lever de allerede op til kravene. Det er den hollandske kunsthandel, som stadig har kraftige argumenter i mod. Legêne sluttede med overvejelser over det skisma, som ligger i tidens kommercialisering og fokus på privatisering, som tydeligt understøttes af kunstmarkedets fokus på det at eje kulturarv som et livsstilsparameter, og så nødvendigheden af at definere kulturarven som et offentligt ansvar, tydeligt set $\mathrm{i}$ et skift i ordbrug, på engelsk fra cultural property til cultural heritage.

\section{EN KUNSTHANDEL BASERET PÅ LØGN OG KRIMINALITET}

Forskningsjournalisten Peter Watson kom med et indlæg med titlen "Why Nice People Tell Lies", hvor han fokuserede på tilfældighedernes spil og pengenes magt. Hvis ikke det havde været for en række tilfælde, samtidige undersøgelser og dødsfald, var det måske ikke lykkedes at optrevle det italienske netværk, 
som har domineret handelen $\mathrm{i}$ de seneste 30 år, og som Watson beskriver i bogen The Medici Conspiracy (Watson 2006). Desværre ser det ikke ud til, at det har betydet en reduktion i udbuddet på markedet: ifølge Watson har auktionshuset Bonhams overtaget en stor del af de genstande, som Sotheby's i London solgte indtil huset i 1995 lukkede sin afdeling for klassiske oldsager pga. Watsons afsløringer af medarbejdernes medvirken til og viden om smugleri (Watson 1997). Interessant var omtalen af begrebet "tainted objects", som blev introduceret i britisk lovgivning i 2003. ${ }^{9}$ Formålet var at gøre det strafbart at importere, handle med eller besidde kulturgenstande, hvis der var den mindste mistanke om, at genstande var stjålne, illegalt udgravede eller fjernet fra et monument eller et skibsvrag i strid med gældende lovgivning. Det er væsentligt at fremhæve, at lovgivningen ikke har tilbagevirkende kraft - således kan genstande kun defineres som "tainted" - urene eller befængte hvis de er udgravet eller fjernet fra et monument eller en bygning efter 31 . december 2003 i strid med gældende lovgivning på det tidspunkt.

Kriminalinspektør Kjeld Agerskov Petersen er den centrale person i den danske efterforskning af sager inden for kunst- og kulturarvskriminalitet i Danmark. Han kunne berette om fire tilfælde af fund af smuglet kulturarv fundet i Kastrup lufthavn inden for det sidste år og i alle tilfælde fik personerne udleveret genstandene igen. Den danske ratifikation af UNESCO-konventionen viser her sin svaghed gennem den manglende regulering af importen. Det er politiets håb, at der kommer nogle klare regler desangående $\mathrm{i}$ forbindelse med ratifikationen af UNIDROIT-konventionen. Tolderne tilbageholder nemlig ikke genstandene, fordi de er smuglede, men fordi de skal vurdere momsen! Det vigtigste redskab 127 i politiets arbejde med stjålen kulturarv er databaser over stjålne genstande, hvor Interpols er den vigtigste. Interpol udsender en DVD, men de seneste to måneders indberetninger er tilgængelig via internettet. ${ }^{10}$ Problemet er naturligvis, at disse databaser ikke indeholder informationer om arkæologiske genstande fra illegale udgravninger. Her er det ICOMs Red Lists, som kan bruges som redskab, eller lovgivning omkring importregulering. Men en af de store udfordringer bliver uddannelse af det personale, som skal checke ved grænserne.

\section{KRAV OM MERE LOVGIVNING}

Mødet blev afsluttet af en paneldebat, hvor der var fokus på de nødvendige juridiske tiltag. Det blev fremhævet, at det var nødvendigt at indføre importrestriktioner, hvis UNESCO-konventionen skal fungere, et element som mangler i den danske ratifikation bortset fra kravene i museumsloven. Et andet forslag gik på at gøre handel med og besiddelse af illegale kulturgenstande ulovlig. Det er et forsøg på det, som den engelske lovgivning har indført via begrebet tainted objects. Det betyder samtidig, at der er tale om omvendt bevisbyrde: Her skal en køber bevise en legal proveniens, det er ikke et spørgsmål om, at den illegale skal bevises af den part, som har været udsat for den illegale handling. Det er principielt det samme, som findes i UNIDROIT-konventionen under begrebet $d u e d i$ ligence, dvs. at køberen skal godtgøre, at man har gjort alt menneskeligt muligt for at sikre sig en legal proveniens. Debatten kom således også til at handle om begrebet proveniens. Direktør for Davids Samling, Kjeld von Folsach, indførte her en række argumenter imod opstramning af reglerne, heriblandt museernes 
manglende muligheder for at erhverve genstande og kriminaliseringen af de millioner af genstande uden proveniens på kunstmarkedet. Det var samme argumentation, som han har fremført i forbindelse med den nye danske oversættelse af ICOMs etiske regler (Folsach 2007, Ipsen 2007). Det er tydeligt, at der i den danske museumsverden har været en række vægtige personer, som netop har haft samme holdning i 1970'erne og 1980'erne og været med til at udsætte en dansk ratifikation af UNESCO-konventionen. Som Susan Legêne kunne påvise fra mødet i København i 1982, så var det en generel holdning i de europæiske lande. Der er inden for de seneste 15 år sket et markant skift i museumsverdenen, og som både det hollandske og danske eksempel viser, så er der stor opbakning i museumsverdenen for at ratificere de nødvendige konventioner.

Den store udfordring i Danmark, men også globalt, bliver at skabe det samme holdningsskifte hos de private samlere. Det er endnu ikke sket, for det er i høj grad her markedet finder sine købere. Som allerede nævnt er der ikke noget overblik over dette i Danmark, men bl.a. Lyngbysagen viser, at en ratifikation af UNIDROIT-konventionen er nødvendig for at kunne retsforfølge private samlere, som ikke overholder de forskellige landes regler om eksport af deres kulturarv. Mødets effekt og positive resultat lå dermed i kulturministerens bekendtgørelse af en fremtidig ratifikation og den konvention. Arbejdet med at skabe et holdningsskifte blandt private handlende og samlere bør dog fremover have høj prioritet hos arkæologer, museumsfolk og politikere for effektivt at kunne medvirke til en beskyttelse af verdens kulturarv.

\section{NOTER}

1. Se f.eks. Dagbladet Information 16.6, 7.7, 10.7. 2006. Politiken 2.12, 3.12., 12.12, 17.12. 2006. Sagen om villaen i Lyngby er nu afsluttet, idet der ikke bliver rejst sag mod samleren i Danmark (Politiken 12.4.2007). Det er ikke lykkedes at finde beviser for, at genstande er ulovligt udført og handlet. Ifølge ejeren Jan Erik Pelle indkøbte han selv genstandene i 1970'erne, hvor han opholdt sig i en længere periode i Peru. Ejeren vil nu kræve en erstatning på 10 millioner kroner, fordi hans genstande er blevet beslaglagt.

2. Convention for the Protection of Cultural Property in the Event of Armed Conflict with Regulations for the Execution of the Convention 1954.

3. En dansk oversættelse af konventionen, notat af kulturministeren fra 27.11.2002 samt udredelse af de lovmæssige implikationer i Danmark kan findes på følgende hjemmeside: http://www.folketinget.dk/Samling/20021/udvbilag/KUU/Alm del_bilag118.htm (set 12.4.2007)

4. UNIDROIT er forkortelsen for International Institute for the Unification of Private Law, som fik i opdrag af UNESCO at udforme et udkast til en konvention som supplement til UNESCO konventione fra 1972.

5. Se Ministerens pen marts07: http://www.kum.dk/sw55596.asp (set 18.4.2007)

6. Se Politiken 13. april: Politiet mangler beviser.

7. Lundén 1999; Lundén 2004. I samarbejde med Channel 4 lavede Lunden dokumentaren i gravrøvernes spor, som er blevet vist i svensk og dansk tv. Se anmeldelse af J. Doole, Culture without Context 7, autumn 2000.

8. Dagbladet Information 10. juli 2006, 5.

9. Se Dealing with tainted cultural objects. Guidance in dealing with cultural objects (offence), Act 2003, Department for Culture, Media and Sport. Cultural Property Unit. 
10. Se http://www.interpol.int/Public/

WorkOfArt/Search/RecentThefts.asp

\section{LITTERATUR:}

Bogdanos, Matthew: The Casualties of War: The Truth About the Iraq Museum, American Journal of Archaeology 109, 3, 2005, 477-526.

Folsach, Kjeld von: Nogle kommentarer og overvejelser i anledning af ICOM's Etiske Regler, Danske Museer 2007, 1, 11-13.

Dealing with tainted cultural objects. Guidance in dealing with cultural objects (offence), Act 2003, Department for Culture, Media and Sport. Cultural Property Unit.

Ipsen, Merete: ICOM, internationale samarbejder og etiske regler, Danske Museer 2007, 1, 14-15.

Lundén, Staffan \& Leif Häggström, Forntid till salu. Rovgrävning och handel med kulturföremål i och utanför Sverige, Fornvännen 94, 1999, 89103.

Lundén, Staffan: "The scholar and the market. Swedish scholarly contributions to the destruction of the world's archaeological heritage", in (ed.)

Karlsson, H., Swedish archaeologists on ethics, Lindome, Bricoleur Press 2004, 197-247.
Nørskov, Vinnie: Greek Vases in New Contexts. The Collecting and Trading of Greek Vases - An Aspect of the Modern Reception of Antiquity. Aarhus University Press: Aarhus 2002.

Schipper, Friedrich T.: The Protection and Preservation of Iraq's Archaeological Heritage, Spring 1991-2003, American Journal of Archaeology 109, 2, 2005, 250-272.

Watson, Peter: Sotheby's. Inside Story. Bloomsbury: London 1997.

Watson, Peter \& Cecilia Todeschini: The Medici Conspiracy. The Illicit Journey of Looted Antiquities. Public Affairs: New York 2006.

*Vinnie Nørskov, lektor og museumsleder Antikmuseet, koordinator for Masteruddannelsen i Museologi ved Center for Museologi, Aarhus Universitet, og bestyrelsesmedlem af Dansk ICOM.

Adresse: Antikmuseet, Aarhus Universitet, Victor Albecksvej, bygn. 1414, 8000 Arhus C. Email:klavn@hum.au.dk 